\title{
Current Concepts in Stereotactic Radiosurgery - A Neurosurgical and Radiooncological Point of View
}

\author{
J. Vesper ${ }^{1 *}$, E. Bölke2*, C. Wille ${ }^{1}$, P. A. Gerber ${ }^{2}$, C. Matuschek ${ }^{1}$, M. Peiper ${ }^{3}$, H. J. Steiger ${ }^{1}$, \\ W. Budach ${ }^{2}$, G. Lammering ${ }^{4}$
}

\begin{abstract}
${ }^{1}$ Department of Neurosurgery, ${ }^{2}$ Department of Radiation Oncology, ${ }^{3}$ Department of Surgery, University of Düsseldorf, Germany, ${ }^{4}$ Maastro Clinic (Radiation Oncology), Maastricht, The Netherlands
\end{abstract}

\begin{abstract}
Stereotactic radiosurgery is related to the history of "radiotherapy" and "stereotactic neurosurgery". The concepts for neurosurgeons and radiooncologists have been changed during the last decade and have also transformed neurosurgery. The gamma knife and the stereotactically modified linear accelerator (LINAC) are radiosurgical equipments to treat predetermined intracranial targets through the intact skull without damaging the surrounding normal brain tissue. These technical developments allow a more precise intracranial lesion control and offer even more conformal dose plans for irregularly shaped lesions. Histological determination by stereotactic biopsy remains the basis for any otherwise undefined intracranial lesion. As a minimal approach, it allows functional preservation, low risk and high sensitivity. Long-term results have been published for various indications. The impact of radiosurgery is presented for the management of gliomas, metastases, brain stem lesions, benign tumours and vascular malformations and selected functional disorders such as trigeminal neuralgia. In AVM's it can be performed as part of a multimodality strategy including resection or endovascular embolisation. Finally, the technological advances in radiation oncology as well as stereotactic neurosurgery have led to significant improvements in radiosurgical treatment opportunities. Novel indications are currently under investigation. The combination of both, the neurosurgical and the radiooncological expertise, will help to minimize the risk for the patient while achieving a greater treatment success.
\end{abstract}

\section{INTRODUCTION / HISTORY}

The term "radiosurgery" refers to a combination of principles and methods derived from "radiotherapy" and "stereotactic neurosurgery". Stereotaxy is defined as "operating in a 3-dimensional space with precalculated directions (trajectories)". The history of stereotaxy is closely connected to the history of neurosurgery itself.

Already in 1908 Horsley and Clarke developed the first stereotactic apparatus in order to precisely locate

\footnotetext{
*J. Vesper and E. Bölke: equal contribution
}

the cerebellum of the rat. They included coordinates from countless brain sections for orientation within the skull. The next milestone was the development of a stereotactic system in humans by Spigel and Wycis in the late 1940 's, designed to treat movement disorders in humans for the first time. Herein, help-structures like the foramina of Monroi, the pineal gland and both the anterior and posterior commissure were defined as targets in the basal ganglia by means of pneumatocephalograms [60]. Finally, Lars Leksell and Traugott Riechert, and also Robert and Wells established frame based stereotactic methods on the basis of coordinates of linear computertomography data. This technique remains the gold standard for stereotactic planning up until now $[18 ; 94 ; 112]$.

However, with the introduction of new imaging modalities new frame materials, i.e. titanium, carbon or ceramics, became necessary [112]. Importantly, the introduction of image fusion software has enabled the use of combined imaging techniques, i.e. CT, PET, SPECT, MRI, which further improved the quality and precision of stereotactic techniques $[15 ; 79 ; 146 ; 153]$.

However, despite the significant progress in the diagnostic accuracy of modern imaging modalities, the histological determination of brain pathologies remains necessary in most cases, especially if a radiosurgical treatment is planned. Reasons for the failure of stereotactic radiosurgery in achieving an adaequate tumor control include an inadequate visualization of the tumor, a lack of intraoperative 3-D (volumetric) imaging, or an insufficient or limited dose (e.g. due to proximity to the brainstem) $[21 ; 29 ; 33 ; 47 ; 51 ; 58 ; 68 ; 145$; 154].

The principles of radiosurgery were developed in 1951 by Leksell. This technical realization led to the development of the gamma knife and the stereotactically modified linear accelerator (LINAC). The gamma knife and the LINAC are radiosurgical equipments used to treat predetermined intracranial targets through the intact skull without damaging the surrounding normal brain tissue. Gamma knife radiosurgery involves the stereotactic target localization with the Leksell frame and subsequent closed-skull single-treatment session irradiation of a lesion with multiple highly focused gamma ray beams produced from 60Co sources. The hemispherical array of sources, the large number of small-diameter beams, and the steep dose 
gradients surrounding a targeted lesion bear the complexicity of the physical characterization of the radiation field. LINAC systems appear to be advantageous in terms of cost, the variety of collimator sizes available and the sophistication of computerized dose planning. Currently, further improvements in conformal LINAC treatment techniques are being developed and implemented, which will further boost the entire field of radiosurgery by offering even more conformal dose plans for irregularly shaped lesions. In addition, LINAC systems are also being adapted for stereotactically focused fractionated radiotherapy and for stereotactic radiation treatments in other parts of the body [13; 14; 44; 137].

\section{STEREOTACTIC BIOPSY}

There is no doubt that the histological determination of a brain pathology remains to be a basic necessity prior to any therapeutic intervention. Knowledge of the exact histology allows better predictions of the prognosis of intracranial lesions, to name only one advantage. Stereotactic biopsy is indicated in the vast majority of detected intracranial lesions, if not otherwise defined. Notably, novel, more sophisticated imaging techniques enable the detection of intracranial pathologies at earlier stages. Consequently, microsurgical approaches in order to reduce intracranial masses are required less $[5 ; 7 ; 12 ; 27 ; 32 ; 36 ; 55 ; 83 ; 108 ; 110$; $111 ; 147]$.

A retrospective analysis reviewing 5000 stereotactic interventions between 1990 and 2005 demonstrated a diagnostic sensitivity of more than $95 \%$ and an overall complication rate of $<3 \%$ [138]. This stresses the growing importance of accurate stereotactic techniques, which allow a safe and secure proof of pathological features.

Moreover, stereotactic principles were the basis for the development of modern neuronavigational procedures, providing less invasive approaches. Today radiosurgical techniques, representing minimally invasive treatment options, are of specific interest to operative neurosurgeons. Taken together, it is to be expected that navigation and stereotaxy will become "reunified" in the near future $[24 ; 48 ; 71 ; 96 ; 133]$.

\section{Metastases}

Brain metastases occur in one third of all cancer patients. Without any intervention, the prognosis is quite poor with a median survival of only one month [39]. Notably, there is an increasing incidence of brain metastasis as a late complication of extracerebral tumors. Due to the recent improvement in the efficacy of radiotherapy and chemotherapy for primary tumors, today those metastases commonly determine the individual prognosis $[1 ; 34 ; 43 ; 77 ; 103 ; 115 ; 134 ; 135]$. The constraints of the blood-brain barrier limit the intracranial efficacy of most chemotherapeutic agents limiting treatment options to surgery, whole brain irradiation, or stereotactic irradiation [8].

As previously mentioned, in recent years the accuracy of imaging techniques has been steadily improving, enabling the detection of metastases at an earlier stage and at a smaller size. With less morbidity and mortality as compared to open microsurgical procedures, the non-invasive concepts of radiosurgery provide an important therapy option for patients with few lesions. (Fig. 1) [2; 26; 52; 57; 109; 148].

Alternatively, the interstitial brachytherapy with temporary I125 seeds represents an additional option for patients suffering from a single metastasis. The implantation of the seeds can be performed immediately after confirmation of the diagnosis in the operating theatre in a single session procedure. Usually seeds are left in place approximately 25 days and are removed under local anaesthesia $[6 ; 31 ; 33 ; 92 ; 101$; $111 ; 128]$.

\section{MALignANT GLiOMAS}

For patients with malignant glioma clear survival advantages have been demonstrated with postresection external beam radiotherapy. However, there is Level IIII evidence that the use of a radiosurgery boost followed by external beam radiotherapy does not confer benefit in terms of overall survival, local brain control, or quality of life as compared with external beam radiotherapy alone. Notably, radiotherapeutic doses escalating 60 Gy have been shown to solely increase toxicity $[9 ; 11 ; 20 ; 30 ; 35 ; 46 ; 107 ; 113 ; 140 ; 140]$. Neverthless, for these patients the total resection of $>90 \%$ of the "visible" tumor masses, which is defined by contrast enhanced T1 weighted MRI, is a prerequisite. Any further "cytoreduction" in terms of incomplete resection remains out of evidence for outcome and survival. The inefficiency of current treatment modalities is derived from multiple factors, including the diffusely infiltrative nature of the disease, which limits a complete surgical resection, the difficulty in overcoming the blood-brain barrier with systemic therapies, and finally the extreme radioresistant biological nature of malignant glioma cells. Once more the histological proof of a malignant glioma is mandatory. The current standard treatment consists of external beam radiotherapy combined with concomitant and adjuvant temozolomide chemotherapy with respect to clinical and social conditions. The combined and adjuvant administration of temozolomide has been proven to be beneficial in terms of survival in newly diagnosed as well as recurrent malignant brain tumors $[10 ; 17 ; 19$; $25 ; 39 ; 41 ; 56 ; 61 ; 72 ; 89 ; 91 ; 95 ; 117 ; 143 ; 152]$.

Patients with large tumors causing brainstem compression should be initially managed by a surgical decompression of the tumor. Finally, several new promising targeted agents are being explored as potential radiosensitizers, which are currently entering early clinical trials [22].

\section{BRAIN STEM LESIONS}

Due to the poor risk-benefit ratio, many lesions of the brainstem are not being considered for microsurgical resection. Stereotactic biopsies are considered the safest and most reliable method for the histological diagnosis of intraaxial brain stem lesions. Keeping in mind the broad variety of possible neoplasias, the definitive pathological diagnosis permits the choice of 


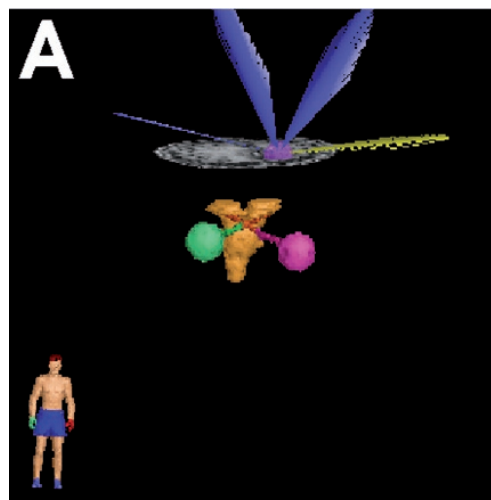

Fig. 1. Stereotactic radiotherapy of a single brain metastasis. A: Visualization of the target volumes for the treatment of a single intracerebral metastasis of a carcinoma of the lung (58 y old female, Adeno-Ca, pT2, pN1 (2/8), cM1). A 3D-reconstruction displaying the metastasis (violett) and proximate sensitive structures (bulbus and tractus opticus $=$ green and pink; brown $=$ brain stem). B: Visualization of photon beams for the target volume based on planning CT applying stereotactic frames. Surrounding isodoses account for 90 percent at 20 Gy. Margins can be reduced to a minimum with regard to the possibility of exact patient positioning.

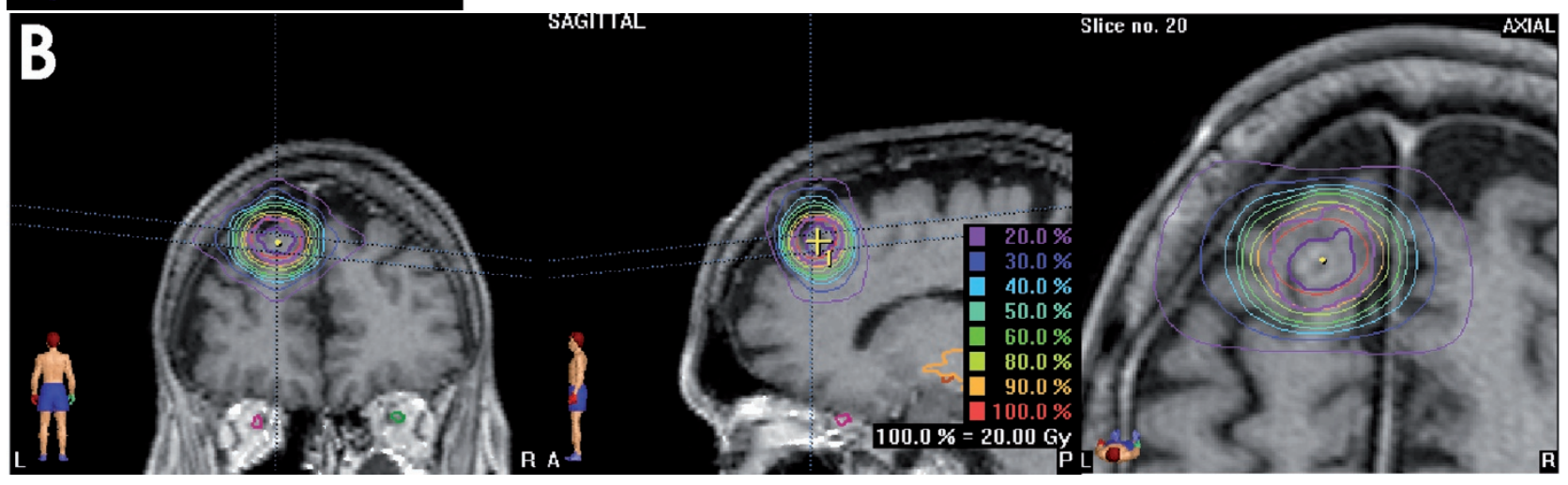

Fig. 2. Patient with mask and stereotactic localizer.

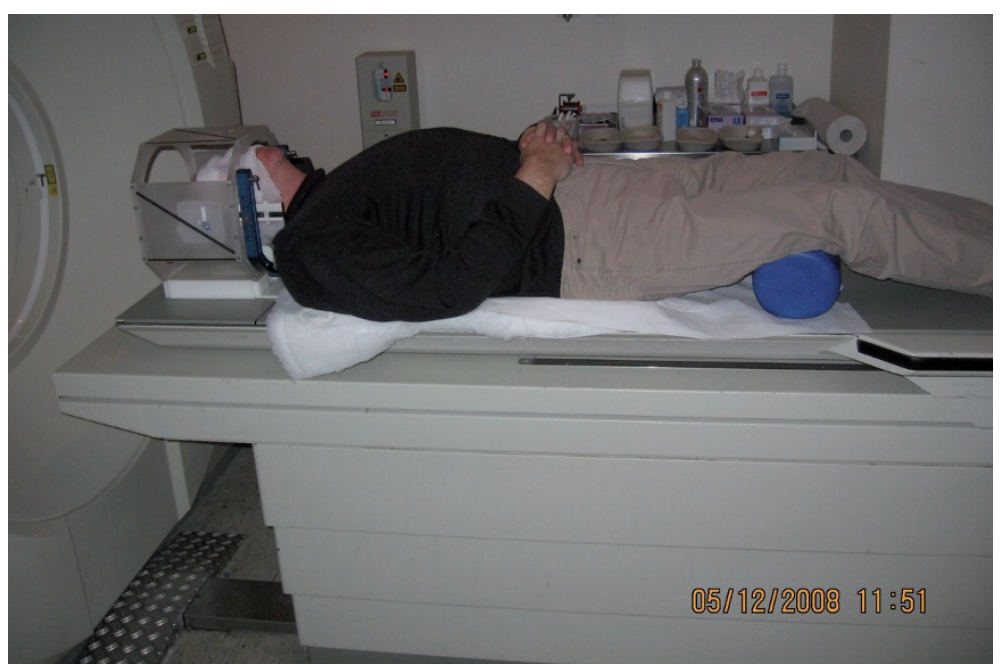

Fig. 3. Patient undergoing stereotactic radiosurgery.

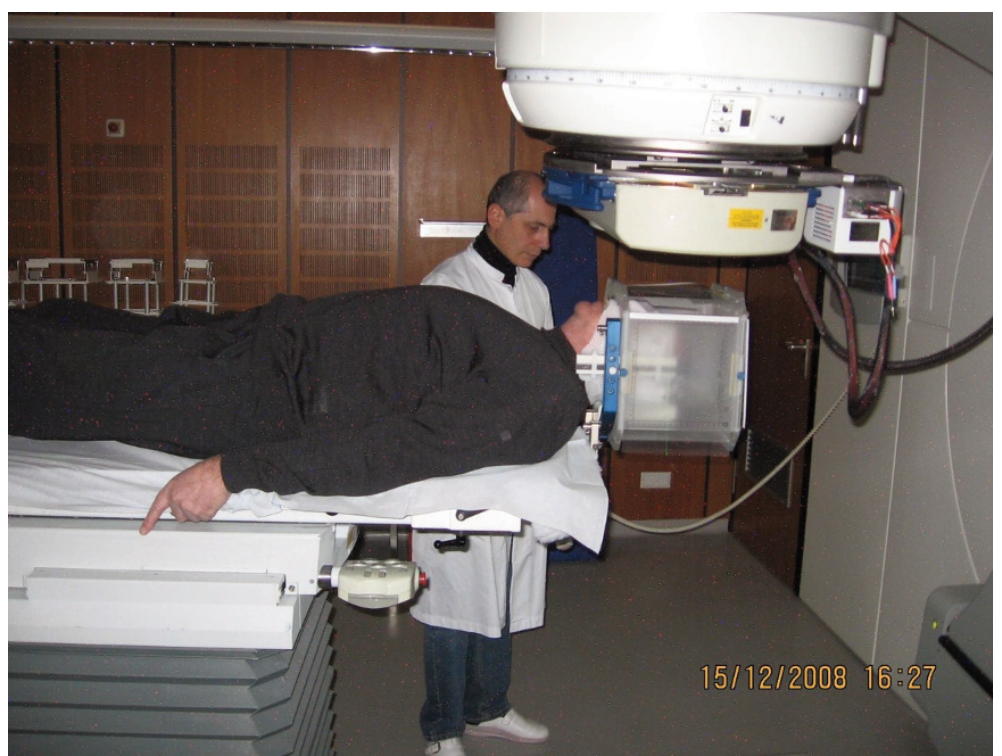


the most adequate therapy. In a series of 50 patients with infiltrating tumors of the brainstem, 30 cases were histologically diagnosed as low-grade astrocytomas, 13 cases as high-grade astrocytomas, 2 cases as primitive neuroectodermic tumors, 2 cases as rhabdoid tumors and 1 case as an ependymoma, and 2 patients with non-specified tumors. No mortality due to stereotactic biopsies were reported. [27]. In the majority of the patients the histological diagnosis led to a therapeutic intervention. Thus, due to the low risk of the procedure, a stereotactic biopsy should be performed in all cases. The radiosurgical treatment of a brainstem lesion might offer a promising non-invasive treatment which is not associated with severe surrounding oedema $[27 ; 74 ; 75 ; 80 ; 149]$.

\section{BENIGN TumORS}

Historically, external beam radiotherapy has been and is still being extensively applied in the treatment of malignant and aggressive intracranial tumors and its important role has been repeatedly verified by improved patient survival and increased tumor control rates. As more modern therapies are being employed in surgery and radiotherapy, attention is now also being directed towards the utility of radiotherapy as either primary or secondary treatment of benign primary brain tumors and meningeomas. Primary tumor treatment encompasses the irradiation of small benign tumors without bioptic confirmation of the histological tumor type. Secondary treatment involves postoperative radiotherapy, with the possibility that less aggressive tumor resections may be performed in areas with a higher probability of resultant neurological deficit. Recent studies suggest that this is not only a possible treatment strategy, but that it may be even superior to a more radical resection strategy in selected cases $[37 ; 45 ; 49 ; 87 ; 99]$.

Stereotactic radiosurgery is typically employed as first line treatment in patients with small to medium size tumors (without symptomatic brainstem compressions). Furthermore, it is also applied to control the growth of recurrent or residual tumor after surgical resection. However, stereotactic radiotherapy, which represents a non-invasive, hypo-fractionated treatment strategy, may also be especially suitable for patients who desire preservation of neurological function (cochlear, facial nerve) and a high rate of tumor growth control. Notably, a local tumor control rate of up to $95 \%$ (5y FU) can be achieved $[37 ; 81 ; 131]$. Meningioma control rates range from 90 to $95 \%$, and the risk of morbidity is low $[38 ; 40 ; 84 ; 93 ; 104]$. The Marseille SRS experience included 1,500 patients, with 1,000 patients having follow-up of more than 3 years. A long-term tumor control rate of $97 \%$, a transient facial palsy of less than $1 \%$, and a probability of functional hearing preservation between 50 and 95\% could be achieved in this large series of patients treated with stereotactic radiosurgery [28; 63; 127$]$.

In another large series of a total of 285 patients, a local tumor control of $95 \%$ was reported $(63 \%$ regression, and $32 \%$ no further tumor growth). After 15 years the tumor control rate still remained above $90 \%$ at $93.7 \%$. In $5 \%$ of the patients a delayed tumor growth could be identified. A surgical resection was performed after radiosurgery in 13 patients (5\%). None of the patients developed a radiation-induced tumor. Eighty-one percent of the patients were still alive at the time of this analysis with a mean follow-up time of 10 years [59A]. In patients undergoing treatment for acoustic neuromas, a normal facial nerve function was maintained in $95 \%$ of patients who had normal function before. Other authors also reported on comparable results [49;66;87].

A further indication for radiosurgical therapy in benign tumors is the interstitial treatment of hypothalamic hamartomas with temporarly implanted iodine seeds (also called brachytherapy). These tumors often become symptomatic with gelastic seizures. SchulzeBohnhage et al. found that 11 out of 24 patients were seizure free or experienced a seizure reduction of at least $90 \%$ after a mean follow-up period of 24 -months following the last interstitial radiosurgical treatment. Notably, the duration of epilepsy prior to radiosurgery negatively influenced this outcome. Moreover, also seizure-patients who present at younger ages $(<15$ y) can be successfully treated with brachytherapy. I125 seed implantation as a radiosurgical technique is predominantly applied for this indication due the advantage of continuous dose application and the possibility of immediate interruption of therapy in cases of side effects, e.g. alteration of the optical tract $[4 ; 42 ; 73$; $123 ; 129 ; 130 ; 141]$.

\section{AVM}

Radiosurgery has been proven to be succesful in the treatment of small arteriovenous malformations (AVMs) of the brain $[16 ; 85 ; 139 ; 142 ; 144 ; 150]$. Until now, digital subtraction angiography (DSA) has been a mandatory tool for the planning of these interventions. By integrating different imaging modalities in the planning and follow-up procedure, e.g. MRI, many side effects can be avoided [64]. However, due to the often significant volume of healthy tissue being irradiated in cases of larger AVM lesions, reduced radiation doses would be preferable in order to minimize the rate of irreversible radiation injuries. On the other hand, lower radiation doses lead to lower obliteration rates. Thus, several strategies have been developed in the past decade to overcome these dose-volume problems with larger AVMs, including reduced prescription doses, volume fractionation and fractionated stereotactic radiotherapy treatments. AVMs with a volume of $\sim>3 \mathrm{ml}$ can be completely obliterated (obliteration rate $72-96 \%$ ) [76], whereas in larger AVMs complication rate and obliteration rate still remain unsatisfactory, especially in AVM's $>10 \mathrm{ml}$. [114]. However, recent optimistic reports suggest a benefit of conventional single-dose stereotactic radiosurgery (SRS). Radiosurgery with marginal dose or peripheral dose around 12 Gy rarely obliterates AVMs and yet most lesions diminish in size after SRS. Higher doses may be reapplied to any residual nidi after an adequate follow-up period $[64,76]$. However, long-term data show that some authors retreat the patients with lower doses with lesions that failed to completely obliterate in the first place [100; 121]. 
Volume segmentation divides AVMs into smaller segments in order to irradiate them separately. Target volumes of only $5-15 \mathrm{ml}$ irradiated with doses of more than $15 \mathrm{~Gy}$ can reduce the irradiated volume delivered to the surrounding brain tissue $[50 ; 76 ; 120]$. Furthermore, fewer radiation injuries have been reported with fractionated stereotactic radiotherapy compared to standard radiosurgery $[16 ; 69 ; 85 ; 98$; 136; 144]. Advances in AVM localization, dose homogeneity and dosimetry and fractionated radiotherapy regimen have refocused the interest in stereotactic radiotherapy. A recently published study of Han et al. on 218 patients with a follow-up of $>2$ years provides a focus on the analysis of the radiation injury rate depending on the AVM volume. Investigators dispensed 25 Gy for small $\left(<4 \mathrm{~cm}^{3}\right)$ and medium size $\left(4-14 \mathrm{~cm}^{3}\right)$ AVMs, and $10 \mathrm{~Gy}$ for larger AVMs $\left(>14 \mathrm{~cm}^{3}\right)$. The overall obliteration rate was $66.4 \%, 81.7 \%$ for small, $53.1 \%$ for medium and $12.5 \%$ for large AVMs. The authors reported an acceptable complication rate of $1.7 \%-17.4 \%$, depending on the size of the AVM [65]. The extended latency period between treatment and occlusion, about 5 years for emerging techniques (such as salvage, staged volume, and hypofractionated radiotherapy), exposes the patient to the risk of haemorrhage during that period. Nevertheless, improvements in dose planning and target delineation will continue to improve the prognosis in patients suffering from inoperable AVM's [16; 69; 85; 98; 136; 144].

\section{OTHER INDICATIONS}

Especially in the field of functional neurosurgery more indications for radiosurgery are emerging. Successful treatments of trigeminal neuralgia have been reported with radiosurgery of the ganglion gasseri in patients with typical trigeminal neuralgia but also with facial pain due to multiple sclerosis and petroclival meningeomas with infiltration of the trigeminal nerve. Facial pain has become a common indication for radiosurgery with an acceptable rate for hypaesthesia and a meaningful relief of pain in the vast majority of the treated patients $[88 ; 105 ; 118 ; 119 ; 125 ; 132]$. The overall failure rate is about $15 \%$, which is approximately in the same as for decompression. Chen et al. identified preoperative factors which can determine the outcome for pain control: The response to anticonvulsant medication has been regarded as the single most important prognostic indicator for treatment success $[3 ; 23 ; 53 ; 54 ; 59 \mathrm{~B} ; 62 ; 67 ; 70 ; 78 ; 82 ; 86 ; 90$; $97 ; 102 ; 106 ; 116 ; 118 ; 122 ; 124 ; 126 ; 151]$.

\section{SUMMARY}

Radiosurgery is enjoying an increasing popularity since the last decade in terms of neurosurgical treatment opportunities but also in terms of treatment options for brain metastases. External beam and interstitial radiosurgery have been implemented as commonly applied treatment techniques in radiation oncology as well as neurosurgery due to significant improvements in therapy efficacy, technological safety (smaller multileaf collimators), as well as dose homogeneity provided by the newer LINAC generations and newer gener- ation radioactive seeds. Technological advances provide larger treatment flexibility. Apart from the treatment of oncologic processes newer indications also include the management of AVMs and pain syndromes within the functional neurosurgical field.

Technological advances in stereotactic neurosurgery not only lead to higher accuracy and safety in planning of both the target coordinates and trajectories (way to the target) but also provide superior and sophisticated methods for defining any intracranial target volume. Correspondingly, current developments in radiosurgery are in part a result of the long tradition of stereotaxy, which today could be considered as an inert component of stereotactic neurosurgery.

In conclusion, the technological advances in radiation oncology as well as stereotactic neurosurgery have led to significant improvements in radiosurgical treatment opportunities, which will certainly lead to further expansions in treatment opportunities for radiosurgery. Combining both, the expertise of the long tradition of sterotaxy in the field of neurosurgery and the expertise of highly conformal irradiation in the field of radiation oncology, will certainly yield to further improvements in the treatment success for our patients, while minimizing the risk for irreversible radiation injuries.

Acknowlegement: We would like to thank Ethelyn Rusnak Clinical Assistant Professor, Department of Anesthesiology State University of New York at Buffalo for reading and correcting the manuscript.

\section{REFERENCES}

1. Stereotactic radiosurgery for multiple or recurrent brain metastases. Tecnologica. 9-10, 1995

2. Towards Minimally Invasive Neurosurgery. 1st Asian Congress of Stereotactic, Functional and Computer-Assisted Neurosurgery. Singapore, December 11-14, 1994. Abstracts. Stereotact Funct Neurosurg. 64: 57-100, 1995

3. Abram S, Rosenblatt P, Holcomb S: Stereotactic radiation techniques in the treatment of acoustic schwannomas. Otolaryngol Clin North Am. 40:571-88, ix, 2007

4. Addas B, Sherman EM, Hader WJ: Surgical management of hypothalamic hamartomas in patients with gelastic epilepsy. Neurosurg Focus. 25:E8, 2008

5. Adler JR, Cox RS, Kaplan I, et al: Stereotactic radiosurgical treatment of brain metastases. J Neurosurg. 76: 444-449, 1992

6. Alesch F, Hawliczek R, Koos WT: Interstitial irradiation of brain metastases. Acta Neurochir. Suppl 63: 29-34, 1995

7. Alesch F, Pappaterra J, Trattnig S, et al: The role of stereotactic biopsy in radiosurgery. Acta Neurochir. Suppl 63: 20-24, 1995

8. Andrews DW: Current neurosurgical management of brain metastases. Semin Oncol. 35: 100-107, 2008

9. Ashamalla H, Zaki B, Mokhtar B, et al: Fractionated stereotactic radiotherapy boost and weekly paclitaxel in malignant gliomas clinical and pharmacokinetics results. Technol Cancer Res Treat. 6: 169-176, 2007

10. Bauman GS, Cairncross JG: Multidisciplinary management of adult anaplastic oligodendrogliomas and anaplastic mixed oligo-astrocytomas. Semin Radiat Oncol. 11: 170-180, 2001 
11. Black P: Management of malignant glioma: role of surgery in relation to multimodality therapy. J Neurovirol. 4: 227-236, 1998

12. Blond S, Lejeune JP, Dupard T, et al: The stereotactic approach to brain stem lesions: a follow-up of 29 cases. Acta Neurochir. Suppl (Wien) 52: 75-77, 1991

13. Bova FJ, Goetsch SJ: Modern linac stereotactic radiosurgery systems have rendered the Gamma Knife obsolete. Med Phys. 28: 1839-1841, 2001

14. Branch CL, Jr., Coric D, Olds W, et al: Stereotactic radiosurgery. A review of "gamma knife" and "linac knife" technology and the unit at the Wake Forest University Medical Center. N C Med J. 53: 395-399, 1992

15. Brucke T, Djamshidian S, Bencsits G, et al: SPECT and PET imaging of the dopaminergic system in Parkinson's disease. J Neurol. 247 Suppl 4: IV/2-IV/7, 2000

16. Buis DR, Lagerwaard FJ, Barkhof F, et al: Stereotactic radiosurgery for brain AVMs: role of interobserver variation in target definition on digital subtraction angiography. Int J Radiat Oncol Biol Phys. 62: 246-252, 2005

17. Burton E, Prados M: New chemotherapy options for the treatment of malignant gliomas. Curr Opin Oncol. 11: 157-161, 1999

18. Carini S, Scielzo G, Grillo RF, et al: Halo ring supporting the Brown-Roberts-Wells stereotactic frame for fractionated radiotherapy. Acta Neurochir. (Wien) 129: 92-96, 1994

19. Carpentier AF: Neuro-oncology: the growing role of chemotherapy in glioma. Lancet Neurol. 4:4-5, 2005

20. Carpentier AF: Neuro-oncology: the growing role of chemotherapy in glioma. Lancet Neurol. 4:4-5, 2005

21. Chang EL, Shiu AS, Mendel E, et al: Phase I/II study of stereotactic body radiotherapy for spinal metastasis and its pattern of failure. J Neurosurg Spine 7: 151-160, 2007

22. Chang JE, Khuntia D, Robins HI, et al: Radiotherapy and radiosensitizers in the treatment of glioblastoma multiforme. Clin Adv Hematol Oncol. 5: 894-15, 2007

23. Chang JW, Kim SH, Huh R, et al: The effects of stereotactic radiosurgery on secondary facial pain. Stereotact Funct Neurosurg. 72 Suppl 1: 29-37, 1999

24. Chang SD, Main W, Martin DP, et al: An analysis of the accuracy of the CyberKnife: a robotic frameless stereotactic radiosurgical system. Neurosurgery. 52: 140-146, 2003

25. Chatel M, Lebrun C, Frenay M: Chemotherapy and immunotherapy in adult malignant gliomas. Curr Opin Oncol. 5: 464-473, 1993

26. Chernov M, Kamikawa S, Toledo R, et al: Minimally invasive management of the third ventricle glioma in a patient without hydrocephalus: neurofiberscopic biopsy followed by gamma knife radiosurgery. Minim Invasive Neurosurg. 47: 238-241, 2004

27. Chico-Ponce dL, Perezpena-Diazconti M, Castro-Sierra E, et al: Stereotactically-guided biopsies of brainstem tumors. Childs Nerv Syst. 19: 305-310, 2003

28. Chin LS, Szerlip NJ, Regine WF: Stereotactic radiosurgery for meningiomas. Neurosurg Focus. 14: e6, 2003

29. Chitapanarux I, Goss B, Vongtama R, et al: Prospective study of stereotactic radiosurgery without whole brain radiotherapy in patients with four or less brain metastases: incidence of intracranial progression and salvage radiotherapy. J Neurooncol. 61: 143-149, 2003

30. Cho KH, Hall WA, Gerbi BJ, et al: Single dose versus fractionated stereotactic radiotherapy for recurrent high-grade gliomas. Int J Radiat Oncol Biol Phys. 45: 1133-1141, 1999

31. Choudhury AR: Interstitial iodine-125 radiosurgery for cerebral metastases. Br J Neurosurg. 10: 229, 1996

32. Coffey RJ, Lunsford LD: The role of stereotactic techniques in the management of craniopharyngiomas. Neurosurg Clin N Am. 1: 161-172, 1990
33. Dagnew E, Kanski J, McDermott MW, et al: Management of newly diagnosed single brain metastasis using resection and permanent iodine-125 seeds without initial whole-brain radiotherapy: a two institution experience. Neurosurg Focus. 22: E3, 2007

34. Datta R, Jawahar A, Ampil FL, et al: Survival in relation to radiotherapeutic modality for brain metastasis: whole brain irradiation vs. gamma knife radiosurgery. Am J Clin Oncol. 27: 420-424, 2004

35. DeAngelis LM, Burger PC, Green SB, et al: Malignant glioma: who benefits from adjuvant chemotherapy? Ann Neurol. 44: 691-695, 1998

36. Dempsey PK, Kondziolka D, Lunsford LD: Stereotactic diagnosis and treatment of pineal region tumours and vascular malformations. Acta Neurochir. (Wien) 116:1422, 1992

37. DiBiase SJ, Chin LS: Stereotactic radiosurgery for benign neoplasms. Technol Cancer Res Treat. 2: 127-134, 2003

38. DiBiase SJ, Kwok Y, Yovino S, et al: Factors predicting local tumor control after gamma knife stereotactic radiosurgery for benign intracranial meningiomas. Int $\mathrm{J}$ Radiat Oncol Biol Phys. 60: 1515-1519, 2004

39. Dropcho EJ: Novel chemotherapeutic approaches to brain tumors. Hematol Oncol Clin North Am. 15: 1027 1052, 2001

40. Dufour H, Muracciole X, Metellus P, et al: Long-term tumor control and functional outcome in patients with cavernous sinus meningiomas treated by radiotherapy with or without previous surgery: is there an alternative to aggressive tumor removal? Neurosurgery. 48: 285294, 2001

41. Dunkel IJ, Finlay JL: High-dose chemotherapy with autologous stem cell rescue for brain tumors. Crit Rev Oncol Hematol. 41: 197-204, 2002

42. Dunoyer C, Ragheb J, Resnick T, et al: The use of stereotactic radiosurgery to treat intractable childhood partial epilepsy. Epilepsia. 43: 292-300, 2002

43. Eichler AF, Loeffler JS: Multidisciplinary management of brain metastases. Oncologist. 12: 884-898, 2007

44. Ekstrand KE, Hinson WH, Bourland JD, et al: The use of a Leksell-BRW adapter for linac radiosurgery as an adjunct to Gamma Knife treatment. Phys Med Biol. 48: 4105-4110, 2003

45. Elia AE, Shih HA, Loeffler JS: Stereotactic radiation treatment for benign meningiomas. Neurosurg Focus. 23: E5, 2007

46. Ernst-Stecken A, Ganslandt O, Lambrecht U, et al: Survival and quality of life after hypofractionated stereotactic radiotherapy for recurrent malignant glioma. J Neurooncol. 81: 287-294, 2007

47. Ertl A, Saringer W, Heimberger K, et al: Quality assurance for the Leksell gamma unit: considering magnetic resonance image-distortion and delineation failure in the targeting of the internal auditory canal. Med Phys. 26: 166-170, 1999

48. Ewend MG, Morris DE, Carey LA, et al: Guidelines for the initial management of metastatic brain tumors: role of surgery, radiosurgery, and radiation therapy. J Natl Compr Canc Netw. 6: 505-513, 2008

49. Flickinger JC, Kondziolka D, Lunsford LD: Radiosurgery of Benign Lesions. Semin.Radiat Oncol. 5: 220224, 1995

50. Flickinger JC, Kondziolka D, Maitz AH, et al: An analysis of the dose-response for arteriovenous malformation radiosurgery and other factors affecting obliteration. Radiother Oncol. 63: 347-354, 2002

51. Foote RL, Pollock BE, Link MJ, et al: Leksell Gamma Knife coordinate setting slippage: how often, how much? J Neurosurg. 101: 590-593, 2004 
52. Forster DM, Kemeny AA, Pathak A, et al: Radiosurgery: a minimally interventional alternative to microsurgery in the management of acoustic neuroma. Br J Neurosurg. 10: 169-174, 1996

53. Fountas KN, Smith JR, Lee GP, et al: Gamma Knife stereotactic radiosurgical treatment of idiopathic trigeminal neuralgia: long-term outcome and complications. Neurosurg Focus. 23: E8, 2007

54. Friehs GM, Park MC, Goldman MA, et al: Stereotactic radiosurgery for functional disorders. Neurosurg Focus. 23: E3, 2007

55. Frighetto L, De Salles AA, Behnke E, et al: Image-guided frameless stereotactic biopsy sampling of parasellar lesions. Technical note. J Neurosurg. 98: 920-925, 2003

56. Galanis E, Buckner J: Chemotherapy for high-grade gliomas. Br J Cancer 82: 1371-1380, 2000

57. Gallina P, Francescon P, Cavedon C, et al: Stereotactic interstitial radiosurgery with a miniature $\mathrm{X}$-ray device in the minimally invasive treatment of selected tumors in the thalamus and the basal Ganglia. Stereotact Funct Neurosurg. 79: 202-213, 2002

58. Gallina P, Merienne L, Meder JF, et al: Failure in radiosurgery treatment of cerebral arteriovenous malformations. Neurosurgery. 42: 996-1002, 1998

59A. Gerber PA, Antal AS, Neumann NJ, Matuschek C, Peiper M, Budach W, Bölke E.Neurofibromatosis. Eur J Med Res 14: 102-105, 2009

59B. Gerbi BJ, Higgins PD, Cho KH, et al: Linac-based stereotactic radiosurgery for treatment of trigeminal neuralgia. J Appl Clin Med Phys. 5: 80-92, 2004

60. Gildenberg PL: History of the American Society for Stereotactic and Functional Neurosurgery. Stereotact Funct Neurosurg. 72: 77-81, 1999

61. Gildenberg PL: Multimodality program involving stereotactic surgery in brain tumor management. Stereotact Funct Neurosurg. 74: 179-184, 2000

62. Goss BW, Frighetto L, DeSalles AA, et al: Linear accelerator radiosurgery using 90 gray for essential trigeminal neuralgia: results and dose volume histogram analysis. Neurosurgery. 53: 823-828, 2003

63. Hamm KD, Gross MW, Fahrig A, et al: Stereotactic radiotherapy for the treatment of nonacoustic schwannomas. Neurosurgery. 62: A29-A36, 2008

64. Hamm KD, Klisch J, Surber G, et al: Special aspects of diagnostic imaging for radiosurgery of arteriovenous malformations. Neurosurgery. 62: A44-A52, 2008

65. Han JH, Kim DG, Chung HT, et al: Clinical and neuroimaging outcome of cerebral arteriovenous malformations after Gamma Knife surgery: analysis of the radiation injury rate depending on the arteriovenous malformation volume. J Neurosurg. 109: 191-198, 2008

66. Hartford AC, Loeffler JS: Radiosurgery for benign tumors and arteriovenous malformations of the central nervous system. Front Radiat. Ther Oncol. 35: 30-47, 2001

67. Hasegawa T, Kondziolka D, Spiro R, et al: Repeat radiosurgery for refractory trigeminal neuralgia. Neurosurgery. 50: 494-500, 2002

68. Heck B, Jess-Hempen A, Kreiner HJ, et al: Accuracy and stability of positioning in radiosurgery: long-term results of the Gamma Knife system. Med Phys. 34: 1487-1495, 2007

69. Henkes H, Nahser HC, Berg-Dammer E, et al: Endovascular therapy of brain AVMs prior to radiosurgery. Neurol Res. 20: 479-492, 1998

70. Herman JM, Petit JH, Amin P, et al: Repeat gamma knife radiosurgery for refractory or recurrent trigeminal neuralgia: treatment outcomes and quality-of-life assessment. Int J Radiat Oncol Biol Phys. 59: 112-116, 2004

71. Hlatky R, Jackson EF, Weinberg JS, et al: intraoperative neuronavigation using diffusion tensor MR tractography for the resection of a deep tumor adjacent to the corticospinal tract. Stereotact Funct Neurosurg. 83: 228-232, 2005

72. Hofer S, Herrmann R: Chemotherapy for malignant brain tumors of astrocytic and oligodendroglial lineage. J Cancer Res Clin Oncol. 127: 91-95, 2001

73. Homma J, Kameyama S, Masuda H, et al: Stereotactic radiofrequency thermocoagulation for hypothalamic hamartoma with intractable gelastic seizures. Epilepsy Res. 76: 15-21, 2007

74. Huang CF, Kondziolka D, Flickinger JC, et al: Stereotactic radiosurgery for brainstem metastases. J Neurosurg. 91: 563-568, 1999

75. Hussain A, Brown PD, Stafford SL, et al: Stereotactic radiosurgery for brainstem metastases: Survival, tumor control, and patient outcomes. Int J Radiat Oncol Biol Phys. 67: 521-524, 2007

76. Jones J, Jang S, Getch CC, et al: Advances in the radiosurgical treatment of large inoperable arteriovenous malformations. Neurosurg Focus. 23: E7, 2007

77. Kaal EC, Niel CG, Vecht CJ: Therapeutic management of brain metastasis. Lancet Neurol. 4: 289-298, 2005

78. Kang JH, Yoon YS, Kang DW, et al: Gamma knife radiosurgery for medically refractory idiopathic trigeminal neuralgia. Acta Neurochir. Suppl 101: 35-38, 2008

79. Karger CP, Hipp P, Henze M, et al: Stereotactic imaging for radiotherapy: accuracy of CT, MRI, PET and SPECT. Phys Med Biol. 48: 211-221, 2003

80. Kased N, Huang K, Nakamura JL, et al: Gamma knife radiosurgery for brainstem metastases: the UCSF experience. J Neurooncol. 86: 195-205, 2008

81. Kollova A, Liscak R, Novotny J, Jr., et al: Gamma Knife surgery for benign meningioma. J Neurosurg. 107: 325336, 2007

82. Kondziolka D: Functional radiosurgery. Neurosurgery. 44: 12-20, 1999

83. Kondziolka D, Firlik AD, Lunsford LD: Complications of stereotactic brain surgery. Neurol Clin. 16: 35-54, 1998

84. Kondziolka D, Flickinger JC, Lunsford LD: The principles of skull base radiosurgery. Neurosurg Focus. 24: E11, 2008

85. Kondziolka D, Lunsford LD: The case for and against AVM radiosurgery. Clin Neurosurg. 48: 96-110, 2001

86. Kondziolka D, Lunsford LD, Flickinger JC: Stereotactic radiosurgery for the treatment of trigeminal neuralgia. Clin J Pain. 18: 42-47, 2002

87. Kondziolka D, Nathoo N, Flickinger JC, et al: Longterm results after radiosurgery for benign intracranial tumors. Neurosurgery. 53: 815-821, 2003

88. Kondziolka D, Perez B, Flickinger JC, et al: Gamma knife radiosurgery for trigeminal neuralgia: results and expectations. Arch Neurol. 55: 1524-1529, 1998

89. Kortmann RD, Jeremic B, Weller M, et al: Radiochemotherapy of malignant glioma in adults. Clinical experiences. Strahlenther Onkol. 179: 219-232, 2003

90. Kubicek GJ, Hall WA, Orner JB, et al: Long-term follow-up of trigeminal neuralgia treatment using a linear accelerator. Stereotact Funct Neurosurg. 82: 244-249, 2004

91. Kyritsis AP: Chemotherapy for malignant gliomas. Oncology. (Huntingt) 7: 93-100, 1993

92. Larson DA, Gutin PH, Leibel SA, et al: Stereotaxic irradiation of brain tumors. Cancer. 65: 792-799, 1990

93. Lee JY, Niranjan A, McInerney J, et al: Stereotactic radiosurgery providing long-term tumor control of cavernous sinus meningiomas. J Neurosurg. 97: 65-72, 2002

94. Leksell L: The stereotaxic method and radiosurgery of the brain. Acta Chir Scand. 102: 316-319, 1951 
95. Lesser GJ, Grossman SA: The chemotherapy of adult primary brain tumors. Cancer Treat Rev. 19: 261-281, 1993

96. Levivier M, Massager N, Wikler D, et al: Modern multimodal neuroimaging for radiosurgery: the example of PET scan integration. Acta Neurochir. Suppl 91: 1-7, 2004

97. Liu JK, Apfelbaum RI: Treatment of trigeminal neuralgia. Neurosurg Clin N Am. 15: 319-334, 2004

98. Lo EH: A theoretical analysis of hemodynamic and biomechanical alterations in intracranial AVMs after radiosurgery. Int J Radiat Oncol Biol Phys. 27: 353-361, 1993

99. Lunsford LD, Kondziolka D, Flickinger JC: Stereotactic radiosurgery for benign intracranial tumors. Clin Neurosurg. 40: 475-497, 1993

100. Mavroidis P, Theodorou K, Lefkopoulos D, et al: Prediction of AVM obliteration after stereotactic radiotherapy using radiobiological modelling. Phys.Med.Biol. 47:2471-2494, 2002

101. McDermott MW, Cosgrove GR, Larson DA, et al: Interstitial brachytherapy for intracranial metastases. Neurosurg Clin N Am. 7: 485-495, 1996

102. McNatt SA, Yu C, Giannotta SL, et al: Gamma knife radiosurgery for trigeminal neuralgia. Neurosurgery. 56: 1295-1301, 2005

103. Mintz A, Perry J, Spithoff K, et al: Management of single brain metastasis: a practice guideline. Curr Oncol. 14: 131-143, 2007

104. Muacevic A, Jess-Hempen A, Tonn JC, et al: Clinical quality standards for gamma knife radiosurgery--the Munich protocol. Acta Neurochir. Suppl 91: 25-32, 2004

105. Nettel B, Niranjan A, Martin JJ, et al: Gamma knife radiosurgery for trigeminal schwannomas. Surg Neurol. 62: 435-444, 2004

106. Nicholson M, O'Neil M: Gamma knife stereotactic radiosurgery for treatment of trigeminal neuralgia. Hawaii Dent J. 34: 14-15, 2003

107. Nieder C, Andratschke N, Wiedenmann N, et al: Radiotherapy for high-grade gliomas. Does altered fractionation improve the outcome? Strahlenther Onkol. 180: 401-407, 2004

108. Noren G, Collins VP: Stereotactic biopsy in acoustic tumors. Appl Neurophysiol. 43: 189-197, 1980

109. Ohye C: The idea of stereotaxy toward minimally invasive neurosurgery. Stereotact Funct Neurosurg. 74: 185193,2000

110. Ostertag CB, Kreth FW: Iodine-125 interstitial irradiation for cerebral gliomas. Acta Neurochir. (Wien.) 119: 53-61, 1992

111. Ostertag CB, Kreth FW: Interstitial iodine-125 radiosurgery for cerebral metastases. Br J Neurosurg. 9: 593603, 1995

112. Ostertag CB, Schad LR, Koch R, et al: Titanium Riechert head ring for MR stereotaxy. Technical note. Acta Neurochir. (Wien) 121: 82-85, 1993

113. Palma L: Trends in surgical management of astrocytomas and other brain gliomas. Forum. (Genova) 8: 272-281, 1998

114. Pan DH, Guo WY, Chung WY, et al: Gamma knife radiosurgery as a single treatment modality for large cerebral arteriovenous malformations. J Neurosurg. 93 Suppl 3: 113-119, 2000

115. Patchell RA: The management of brain metastases. Cancer Treat Rev. 29: 533-540, 2003

116. Patwardhan RV, Minagar A, Kelley RE, et al: Neurosurgical treatment of multiple sclerosis. Neurol Res. 28: 320-325, 2006

117. Pech IV, Peterson K, Cairncross JG: Chemotherapy for brain tumors. Oncology. (Huntingt) 12: 537-43, 547, 1998
118. Pollock BE: An evidence-based medicine review of stereotactic radiosurgery. Prog Neurol Surg. 19: 152170, 2006

119. Pollock BE, Iuliano BA, Foote RL, et al: Stereotactic radiosurgery for tumor-related trigeminal pain. Neurosurgery. 46: 576-582, 2000

120. Pollock BE, Kline RW, Stafford SL, et al: The rationale and technique of staged-volume arteriovenous malformation radiosurgery. Int J Radiat Oncol Biol Phys. 48: 817-824, 2000

121. Pollock BE, Kondziolka D, Lunsford LD, et al: Repeat stereotactic radiosurgery of arteriovenous malformations: factors associated with incomplete obliteration. Neurosurgery. 38: 318-324, 1996

122. Pollock BE, Phuong LK, Gorman DA, et al: Stereotactic radiosurgery for idiopathic trigeminal neuralgia. J Neurosurg. 97: 347-353, 2002

123. Quigg M, Barbaro NM: Stereotactic radiosurgery for treatment of epilepsy. Arch Neurol. 65: 177-183, 2008

124. Rand RW: Leksell Gamma Knife treatment of tic douloureux. Neurosurg Clin N Am. 8: 75-78, 1997

125. Regis J, Metellus P, Dufour H, et al: Long-term outcome after gamma knife surgery for secondary trigeminal neuralgia. J Neurosurg. 95: 199-205, 2001

126. Regis J, Metellus P, Hayashi M, et al: Prospective controlled trial of gamma knife surgery for essential trigeminal neuralgia. J Neurosurg. 104: 913-924, 2006

127. Regis J, Roche PH, Delsanti C, et al: Modern management of vestibular schwannomas. Prog Neurol Surg. 20: 129-141, 2007

128. Schulder M, Black PM, Shrieve DC, et al: Permanent low-activity iodine-125 implants for cerebral metastases. J Neurooncol. 33: 213-221, 1997

129. Schulze-Bonhage A, Trippel M, Wagner K, et al: Outcome and predictors of interstitial radiosurgery in the treatment of gelastic epilepsy. Neurology. 71: 277-282, 2008

130. Selch MT, Gorgulho A, Mattozo C, et al: Linear accelerator stereotactic radiosurgery for the treatment of gelastic seizures due to hypothalamic hamartoma. Minim Invasive Neurosurg. 48: 310-314, 2005

131. Shafron DH, Friedman WA, Buatti JM, et al: Linac radiosurgery for benign meningiomas. Int J Radiat Oncol Biol Phys. 43: 321-327, 1999

132. Slavin KV, Nersesyan H, Colpan ME, et al: Current algorithm for the surgical treatment of facial pain. Head Face Med. 3: 30, 2007

133. Solberg TD, Medin PM, Mullins J, et al: Quality assurance of immobilization and target localization systems for frameless stereotactic cranial and extracranial hypofractionated radiotherapy. Int J Radiat Oncol Biol Phys. 71: S131-S135, 2008

134. Sperduto PW: A review of stereotactic radiosurgery in the management of brain metastases. Technol Cancer Res Treat. 2: 105-110, 2003

135. Suh JH, Vogelbaum MA, Barnett GH: Update of stereotactic radiosurgery for brain tumors. Curr Opin Neurol. 17: 681-686, 2004

136. Tercier PA, Aroua A, Mirimanoff RO, et al: Optimisation in stereotactic radiosurgery of AVMs: II. Comparison of arc and MMLC therapy. Z Med Phys. 14: 222229,2004

137. Theodorou K, Stathakis S, Lind B, et al: Dosimetric and radiobiological evaluation of dose distribution perturbation due to head heterogeneities for Linac and Gamma Knife stereotactic radiotherapy. Acta Oncol. 47: $917-$ 927, 2008

138. Tilgner J, Herr M, Ostertag C, et al: Validation of intraoperative diagnoses using smear preparations from stereotactic brain biopsies: intraoperative versus final diagnosis--influence of clinical factors. Neurosurgery. 56: 257-265, 2005 
139. Treuer H, Kocher M, Hoevels M, et al: Impact of target point deviations on control and complication probabilities in stereotactic radiosurgery of AVMs and metastases. Radiother Oncol. 81: 25-32, 2006

140. Tsao MN, Mehta MP, Whelan TJ, et al: The American Society for Therapeutic Radiology and Oncology (ASTRO) evidence-based review of the role of radiosurgery for malignant glioma. Int J Radiat Oncol Biol Phys. 63: $47-55,2005$

141. Unger F, Schrottner O, Feichtinger M, et al: Stereotactic radiosurgery for hypothalamic hamartomas. Acta Neurochir. Suppl 84: 57-63, 2002

142. Valentino V: Radiosurgery in cerebral tumours and AVM. Acta Neurochir. Suppl (Wien) 42: 193-197, 1988

143. van den Bent MJ, Taphoorn MJ, Brandes AA, et al: Phase II study of first-line chemotherapy with temozolomide in recurrent oligodendroglial tumors: the European Organization for Research and Treatment of Cancer Brain Tumor Group Study 26971. J Clin Oncol. 21: 2525-2528, 2003

144. Voges J, Treuer H, Lehrke R, et al: Risk analysis of LINAC radiosurgery in patients with arteriovenous malformation (AVM). Acta Neurochir. Suppl 68: 118-123, 1997

145. Wang L, Jacob R, Chen L, et al: Stereotactic IMRT for prostate cancer: setup accuracy of a new stereotactic body localization system. J Appl Clin Med Phys. 5: 1828, 2004

146. Wara W, Bauman G, Gutin P, et al: Stereotactic radiosurgery in children. Stereotact Funct Neurosurg. 64 Suppl 1: 118-125, 1995

147. Warnke PC, Kopitzki K, Ostertag CB: Interstitial stereotactic radiosurgery. Acta Neurochir. Suppl 88: 4550, 2003

148. Wowra B, Czempiel H, Cibis R, et al: [Profile of ambulatory radiosurgery with the gamma knife system. 1: Method and multicenter irradiation concept]. Radiologe. 37: 995-1002, 1997
149. Yen CP, Sheehan J, Steiner M, et al: Gamma knife surgery for focal brainstem gliomas. J Neurosurg. 106: $8-17,2007$

150. Young CS, Schwartz ML, O'Brien P, et al: Stereotactic radiotherapy for AVMs: the University of Toronto experience. Acta Neurochir. Suppl 63: 57-59, 1995

151. Young RF, Vermulen S, Posewitz A: Gamma knife radiosurgery for the treatment of trigeminal neuralgia. Stereotact Funct Neurosurg. 70 Suppl 1: 192-199, 1998

152. Yung WK: Chemotherapy for malignant brain tumors. Curr Opin Oncol. 2: 673-678, 1990

153. Zeck OF, Fang B, Mullani N, et al: PET and SPECT imaging for stereotactic localization. Stereotact Funct Neurosurg. 64 Suppl 1: 147-154, 1995

154. Zheng LG, Xu DS, Kang CS, et al: Stereotactic radiosurgery for primary trigeminal neuralgia using the Leksell Gamma unit. Stereotact Funct Neurosurg. 76: 2935, 2001

Received: January 2, 2009 / Accepted: February 2, 2009

Address for correspondence:

Prof. Dr. med. Jan Vesper

Funktionelle Neurochirurgie und Stereotaxie

Universitätsklinikum Düsseldorf

Moorenstr. 5

40225 Düsseldorf

Tel.: $\quad+49(0) 211 / 81-18408$

Fax: $\quad+49(0) 211 / 8101518408$

E-mail: jan.vesper@med.uni-duesseldorf.de 